\title{
Hydrological impact assessment on permeable road pavement with subsurface precast micro-detention pond
}

\author{
Norazlina Bateni ${ }^{1,2}$, Sai Hin Lai (iD) 1, Frederik Josep Putuhena², Darrien Yau Seng Mah², Md Abdul Mannan² \& \\ Ren Jie Chin (iD) 3 \\ ${ }^{1}$ Department of Civil Engineering, Faculty of Engineering, University of Malaya, Kuala Lumpur, Malaysia; ${ }^{2}$ Department of Civil Engineering, Faculty of \\ Engineering, Universiti Malaysia Sarawak, Kota Samarahan, Malaysia; and ${ }^{3}$ Department of Civil Engineering, Lee Kong Chian Faculty of Engineering and \\ Science, Universiti Tunku Abdul Rahman, Kajang, Malaysia
}

\section{Keywords}

detention pond; hydrological assessment; permeable pavement; stormwater management; SWMM

\section{Correspondence}

Sai Hin Lai, Department of Civil Engineering, Faculty of Engineering, University of Malaya, 50603 Kuala Lumpur, Malaysia.

Email: laish@um.edu.my

doi:10.1111/wej.12613

\begin{abstract}
The purpose of this paper is to study stormwater management potential of new permeable pavement with subsurface micro-detention storage (PPDS) at low-speed residential suburban area. The main features incorporated permeable pavement of a hollow micro cylinder precast structure with solid hexagon precast concrete as top and bottom covers. The purpose of hollow micro detention design is for rainwater holding and void between the sets is for self-drying through the side and bottom seepage during rain. The hydrological parameters were obtained from laboratory rainfall simulator experiment. The performance was evaluated via simulation with Storm Water Management Model (SWMM). The outcomes from the physical model matched well with SWMM. A case study was then developed to assess the hydrological impact of PPDS with the existing condition and other types of permeable pavements. Significant variance was observed, where PPDS displayed its best hydrological performances for stormwater management with the presence of subsurface detention storage.
\end{abstract}

\section{Introduction}

\section{Background and motivation}

Permeable pavements have been widely used since 1982 in the USA and in the 1990s in Canada, Europe and Japan as a measure to control stormwater (Mosquera and Drake, 1998; Pratt, 1999; Dietz, 2007; O'Sullivan et al., 2011). Permeable pavements have been extremely effective in infiltrating stormwater runoff (Watanabe, 1995; Fach and Geiger, 2005; Zhou and Li, 2008; Bastien et al., 2011; Sañudo-Fontaneda et al, 2013; Barszcz, 2015), significantly reducing runoff volume (Pratt et al., 1989; Davey and Maziliauskas, 2003; Lin et al., 2014; Timm et al., 2018) and minimising peak flow (Price, 1994; Kim et al., 2015; Imteaz et al., 2018; Su et al., 2019). Permeable pavements that commonly used are pervious concrete (PC), porous asphalt (PA) and permeable pavers. PC and PA are permeable variations of concrete or asphalt, where the binding agent coats the aggregate particles without filling the voids between the particles (Kim et al., 2015). Permeable pavers are also commonly known as permeable interlocking concrete pavers (PICP), which are composed of modular units separated by joints filled with open-graded aggregate (ICPI, 2013). Permeable pavements share similar underlying stormwater storage and support structure (USEPA, 2000), assembled with layers of open-graded materials that comprise of surface layer (porous concrete/asphalt and permeable precast modular unit), bedding and reservoir layer (base and subbase) (Shirke and Shuler, 2009; Sañudo-Fontaneda et al., 2014; Aryal et al., 2015).

Nevertheless, the limitation comes with its hydrologicalrelated aspects in terms of clogging thus reduce the permeability rate and its efficiency to reduce stormwater runoff. The permeable pavement is design in layered of porous materials with void capacities from 15\% to 40\% (Kuosa et al., 2013; Kayhanian et al., 2015). This layered characteristic with void spaces of these types of pavement can get clogged when particles build-up and block the connected capillary pores or when they get accumulated in void spaces of permeable pavements (Leming et al., 2007; Kayhanian et al., 2012; Yong et al., 2013). A study by Kayhanian et al. (2012) found that most clogging occurs near the void surface of the permeable pavement. In addition, the literature review reveals that serviceability of the permeable pavements is generally decreased with pavement age as a result of clogging (Kuosa et al., 2013; Kayhanian et al., 2015; Bateni et al., 2019).

Therefore, it is sensible to enhance the design so as to improve the void capacity within the permeable pavement system, which enables a large amount of infiltration into the soil and longer time of clogging. In this study, a modified permeable pavement design is introduced as a 